Received: 24 April 2017

Accepted: 18 August 2017

Published online: 31 August 2017
CIENTIFIC REP

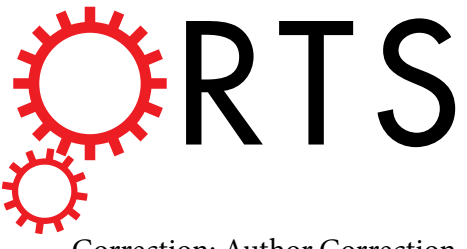

Correction: Author Correction

\section{OPEN The effect of body mass index and physical activity on hypertension among Chinese middle-aged and older population}

Wenzhen $\mathrm{Li}^{1}$, Dongming Wang ${ }^{2,3}$, Chunmei Wu ${ }^{1}$, Oumin $\mathrm{Shi}^{4}$, Yanfeng Zhou ${ }^{1}$ \& Zuxun Lu ${ }^{1}$

Few studies have been conducted to explore the independent and combined associations of body mass index (BMI) and physical activity with risk of hypertension in Chinese population. A cross-sectional study of 5291 individuals (aged $\geq 40$ years) selected using multi-stage sampling method was conducted from October 2013 to December 2015. In the present analysis, 55.64\% of the participants were women, and the mean age of participants was $55.37 \pm 10.56$. Compared with individuals in normal group, the risks of hypertension were nearly double in overweight subjects (odds ratio [OR] 1.77, 95\% confidence interval [CI] 1.53-2.05) and more than three times higher in obese subjects $(3.23,2.62-4.13)$. Multiadjusted odds for hypertension associated with low, moderate, and high physical activity were 1.44 (1.17-1.86), 1.40 (1.09-1.79) and 1.000, respectively. In comparison with normal weight subjects who reported high levels of physical activity, subjects who reported both low levels of physical activity and obesity showed the highest risk of hypertension $(5.89,3.90-8.88)$. In conclusion, both elevated BMI and reduced physical activity appear to play an important role in the risk of hypertension among Chinese middle-aged and older population. The risk of hypertension associated with overweight and obesity can be reduced considerably by increased physical activity levels.

Hypertension is one of the leading causes of global burden of disease and is widely acknowledged as the most common cardiovascular disorder and may account for a large proportion of stroke, coronary heart disease, renal failure and premature mortality ${ }^{1}$, affecting one in four adults in United States ${ }^{2}$ and worldwide ${ }^{3}$. The prevalence of hypertension is increasing globally, and it is estimated that hypertension is likely to rise to $30 \%$ by the year $2025^{3}$. In China, two nationwide blood pressure surveys suggested that $66 \%$ increase in the prevalence of hypertension from 1991 to 2002 with increasing prevalence of obesity and a sedentary lifestyle. The surveys also showed half of the elder people (60 years old and above) had hypertension ${ }^{4,5}$.

Despite of its high prevalence, hypertension has a low rate of successful treatment. In the United States for example, approximately two-thirds of adults with hypertension are either untreated or undertreated ${ }^{6}$. It may due to the known difficulty of successfully treating hypertension as well as its large health burden, more and better primary prevention through lifestyle modifications could become a major public health priority.

Previous studies have suggested that high body mass index (BMI) $)^{7-9}$, and low physical activity ${ }^{10-12}$ are modifiable risk factors for hypertension. However, other studies reported inconsistent results. A prospective study ${ }^{13}$ reported that Harvard college alumni who did not participate in vigorous exercise had a $35 \%$ higher incidence of hypertension than those who were more active. Haapenan et al. ${ }^{14}$ found the intensity of activity was not associated with the risk of hypertension after adjustment for both age and total amount of activity. The Atherosclerosis Risk in Community Study (ARIC) demonstrated the inverse association between leisure time physical activity and risk of hypertension in middle-aged white men, but lack of association in white women ${ }^{15}$. A Japanese prospective

${ }^{1}$ Department of Social Medicine and Health Management, School of Public Health, Tongji Medical College, Huazhong University of Science and Technology, Wuhan, China. ${ }^{2}$ Department of Occupational \& Environmental Health, School of Public Health, Tongji Medical College, Huazhong University of Science and Technology, Wuhan, China. ${ }^{3}$ Wuhan Hospital for the Prevention and Treatment of Occupational Diseases, Wuhan, China. ${ }^{4}$ Hongqiao International Institute of Medicine, Shanghai Tongren Hospital/Faculty of Public Health, Shanghai Jiao Tong University School of Medicine, Shanghai, China. Correspondence and requests for materials should be addressed to Z.L. (email: zuxunlu@yahoo.com) 


\begin{tabular}{|c|c|c|c|c|c|c|c|c|c|}
\hline \multirow[b]{3}{*}{ Characteristics } & \multicolumn{4}{|l|}{ BMI n (\%) } & \multirow[b]{3}{*}{$P$} & \multicolumn{3}{|c|}{ Physical Activity n (\%) } & \multirow[b]{3}{*}{$P$} \\
\hline & \multirow{2}{*}{$\begin{array}{l}\text { Underweight } \\
214(4.04)\end{array}$} & \multirow{2}{*}{\begin{tabular}{|l|} 
Normal \\
$2724(51.48)$ \\
\end{tabular}} & \multirow{2}{*}{\begin{tabular}{|l|} 
Overweight \\
$1876(35.47)$
\end{tabular}} & \multirow{2}{*}{\begin{tabular}{|l|} 
Obese \\
$477(9.02)$ \\
\end{tabular}} & & \multirow{2}{*}{\begin{tabular}{|l|} 
low \\
$3426(64.75)$ \\
\end{tabular}} & \multirow{2}{*}{\begin{tabular}{|l|} 
moderate \\
$1389(26.25)$
\end{tabular}} & \multirow{2}{*}{\begin{tabular}{|l|} 
high \\
$476(9.00)$
\end{tabular}} & \\
\hline & & & & & & & & & \\
\hline age, mean years $( \pm \mathrm{SD})$ & $61.59(12.76)$ & $55.16(10.89)$ & $55.33(9.78)$ & $53.95(9.49)$ & $<0.001$ & $55.37(10.75)$ & $55.37(10.24)$ & $55.37(10.09)$ & 0.998 \\
\hline Sex & & & & & 0.174 & & & & 0.212 \\
\hline male & $82(38.32)$ & $1209(44.38)$ & $854(45.52)$ & $202(42.35)$ & & $1522(44.42)$ & $598(43.05)$ & $227(47.69)$ & \\
\hline female & $132(61.68)$ & $1515(55.62)$ & $1022(54.48)$ & $275(57.65)$ & & $1904(55.58)$ & $791(56.95)$ & $249(53.31)$ & \\
\hline Waist circumference & & & & & $<0.001$ & & & & 0.855 \\
\hline normal & 205 (95.9) & $2138(78.49)$ & $768(40.94)$ & $36(7.55)$ & & $2047(59.75)$ & $818(58.89)$ & $282(59.24)$ & \\
\hline abnormal & $9(4.21)$ & $586(21.51)$ & $1108(59.06)$ & $441(92.45)$ & & $1379(40.25)$ & $571(41.11)$ & $194(40.76)$ & \\
\hline Marital status & & & & & $<0.001$ & & & & 0.024 \\
\hline single & $2(0.93)$ & $36(1.32)$ & $20(1.07)$ & $6(1.26)$ & & $53(1.55)$ & $9(0.65)$ & $2(0.42)$ & \\
\hline married & $177(82.71)$ & $2515(92.33)$ & $1774(94.56)$ & $454(95.18)$ & & $3173(92.62)$ & $1294(93.16)$ & $453(95.17)$ & \\
\hline divorced & $2(0.93)$ & $38(1.40)$ & $13(0.69)$ & $6(1.26)$ & & $31(0.90)$ & $23(1.66)$ & $5(1.05)$ & \\
\hline widowed & $33(15.42)$ & $126(4.63)$ & $65(3.46)$ & $11(2.31)$ & & $160(4.67)$ & $59(4.25)$ & $16(3.36)$ & \\
\hline other & 0 & $9(0.33)$ & $4(0.21)$ & 0 & & $9(0.26)$ & $4(0.29)$ & 0 & \\
\hline Educational level & & & & & $<0.001$ & & & & $<0.001$ \\
\hline Primary school and below & $92(42.99)$ & $631(23.16)$ & $314(16.74)$ & $62(13.00)$ & & $827(24.14)$ & $200(14.40)$ & $72(15.13)$ & \\
\hline Junior middle school & $67(31.31)$ & $955(35.06)$ & $730(38.91)$ & $196(41.09)$ & & $1251(36.51)$ & $526(37.87)$ & $171(35.92)$ & \\
\hline Senior middle school & $36(16.82)$ & $719(26.40)$ & $534(28.46)$ & $139(29.14)$ & & $869(25.36)$ & $416(29.95)$ & $143(30.04)$ & \\
\hline College degree and above & $19(8.88)$ & 419 (15.38) & $298(15.88)$ & $80(16.77)$ & & $479(13.98)$ & $247(17.78)$ & $90(18.91)$ & \\
\hline Smoking status & & & & & 0.001 & & & & 0.016 \\
\hline no & $164(76.64)$ & $2166(79.52)$ & $1563(83.32)$ & $401(84.07)$ & & $2746(80.15)$ & $1143(82.29)$ & 405 (85.08) & \\
\hline yes & $50(23.36)$ & $558(20.48)$ & $313(16.68)$ & $76(15.93)$ & & $680(19.85)$ & $246(17.71)$ & $71(14.92)$ & \\
\hline Drinking status & & & & & 0.281 & & & & 0.451 \\
\hline no & $185(86.45)$ & $2232(81.94)$ & $1527(81.40)$ & $397(83.23)$ & & $2827(82.52)$ & $1125(80.99)$ & $389(81.72)$ & \\
\hline yes & $29(13.55)$ & $492(18.06)$ & $349(18.60)$ & $80(16.77)$ & & 599 (17.48) & $264(19.01)$ & $87(18.28)$ & \\
\hline Diabetes mellitus & & & & & $<0.001$ & & & & 0.004 \\
\hline no & $193(90.19)$ & $2437(89.46)$ & $1651(88.01)$ & $420(88.05)$ & & $3044(88.85)$ & $1253(90.21)$ & $404(84.47)$ & \\
\hline yes & $6(2.80)$ & $148(5.43)$ & $165(8.80)$ & $48(10.06)$ & & $225(6.57)$ & $96(6.91)$ & $46(9.66)$ & \\
\hline unknown & $15(7.01)$ & $139(5.10)$ & $60(3.20)$ & $9(1.89)$ & & $157(4.58)$ & $40(2.88)$ & $26(5.46)$ & \\
\hline
\end{tabular}

Table 1. Characteristics of study population by BMI and physical activity category. BMI, body mass index; SD, standard deviation.

study ${ }^{16}$ showed that the duration of walking to work and other types of physical activity were associated with a reduction in the risk for hypertension in Japanese men. Moreover, few studies were conducted to explore their combined effects on hypertension, especially in Chinese population.

We conducted a cross-sectional study to examine the individual and combined effects between BMI and physical activity in association with hypertension in Chinese middle-aged and older population, which may be an important supplementary on studies of hypertension and help inform more effective interventions.

\section{Results}

Among the 5,291 participants, 55.64\% of the participants were women, and the mean age of participants was $55.37 \pm 10.56,31.90 \%$ of participants were hypertensive. Characteristics of the participants by categories of BMI and physical activity were shown in Table 1. Overall, 2,724 (51.48\%) individuals reported BMI were normal (18.5-23.9), and $477(9.02 \%) \geq 28$, respectively. There were 3,426 (64.75\%) subjects reporting low physical activity, and only $476(9.00 \%)$ reporting high physical activity. There were significant differences between different categories of BMI in most of the covariates and the significant differences between different categories of physical activity were found in the covariates of marital status, educational level, smoking status and diabetes status.

Stratification analyses showed that the association between larger BMI and hypertension risk was noticeable in both of those abnormal waist circumferences and without DM (Table 2). And this association was stronger in males and those with college and above educational level, those ages $<60$ years old, married, nondrinkers and nonsmokers (Table 2). In terms of lower physical activity, the association with hypertension risk was inconsistent and additionally significant among female and individuals with senior middle school educational level and college degree and above. In addition, the association between physical activity and hypertension risk was also found among those without DM, those aged $<60$ years old, married, nondrinkers and nonsmokers. As to waist circumference, abnormal waist with low physical activity got the highest risk (adjusted OR 1.60, 95\% CI 1.14-2.24) (Table 2).

After multivariate adjustment for potential confounders, we found that higher BMI and lower level of physical activity were independently associated with a higher risk of hypertension. Table 3, Fig. 1(a) and (b) showed that the individual effects of BMI and physical activity on hypertension risk. Compared with normal weight subjects, 


\begin{tabular}{|c|c|c|c|c|c|c|c|}
\hline \multirow[b]{2}{*}{ Characteristics (n) } & \multicolumn{4}{|l|}{ BMI } & \multicolumn{3}{|l|}{ Physical Activity } \\
\hline & \begin{tabular}{|l|} 
Underweight \\
\end{tabular} & Normal & Overweight & Obese & low & moderate & high \\
\hline \multicolumn{8}{|l|}{ Age } \\
\hline$<60(3448)$ & $0.53(0.25,1.10)$ & Ref. & $2.05(1.69,2.48)$ & $3.56(2.68,4.73)$ & $1.60(1.16,2.20)$ & $1.60(1.14,2.26)$ & Ref. \\
\hline$\geq 60(1843)$ & $0.52(0.33,0.82)$ & Ref. & $1.41(1.12,1.77)$ & $2.62(1.70,4.03)$ & $1.34(0.96,1.87)$ & $1.19(0.83,1.71)$ & Ref. \\
\hline \multicolumn{8}{|l|}{ Sex } \\
\hline male (2347) & $0.56(0.31,1.03)$ & Ref. & $1.83(1.47,2.27)$ & $3.64(2.51,5.28)$ & $1.37(0.99,1.90)$ & $1.23(0.86,1.75)$ & Ref. \\
\hline female (2944) & $0.54(0.33,0.89)$ & Ref. & $1.68(1.38,2.05)$ & $2.89(2.13,3.92)$ & $1.63(1.18,2.25)$ & $1.63(1.16 .2 .30)$ & Ref. \\
\hline \multicolumn{8}{|l|}{ Waist circumference } \\
\hline normal (3147) & $0.48(0.33,0.75)$ & Ref. & $1.86(1.54,2.25)$ & $2.40(1.17,4.91)$ & \begin{tabular}{|l|}
$1.39(1.02,1.90)$ \\
\end{tabular} & $1.45(1.04,2.03)$ & Ref. \\
\hline abnormal (2144) & $1.51(0.37,6.24)$ & Ref. & $1.64(1.31,2.06)$ & $3.04(2.30,4.01)$ & $1.60(1.14,2.24)$ & $1.39(0.97,1.99)$ & Ref. \\
\hline \multicolumn{8}{|l|}{ Marital status } \\
\hline Single (64) & - & Ref. & $0.72(0.09,5.77)$ & \begin{tabular}{|l|}
$0.56(0.02,20.85)$ \\
\end{tabular} & $0.15(0.01,6.04)$ & $1.09(0.02,57.41)$ & Ref. \\
\hline Married (4920) & $0.57(0.37,0.88)$ & Ref. & $1.78(1.53,2.07)$ & $3.21(2.52,4.09)$ & $1.59(1.25,2.01)$ & $1.49(1.16,1.92)$ & Ref. \\
\hline Divorced (59) & - & Ref. & - & - & - & $0.20(0.01,9.75)$ & Ref. \\
\hline Widowed (235) & $0.49(0.18,1.28)$ & Ref. & $1.27(0.61,2.61)$ & $1.31(0.27,6.35)$ & $0.68(0.22,2.09)$ & $0.89(0.27,2.96)$ & Ref. \\
\hline Other (13) & - & Ref. & - & - & - & - & Ref. \\
\hline \multicolumn{8}{|l|}{ Educational level } \\
\hline Primary school and below (1099) & $0.67(0.37,1.21)$ & Ref. & $1.37(0.98,1.93)$ & $1.29(1.04,3.59)$ & $0.95(0.54,1.67)$ & $1.30(0.71,2.41)$ & Ref. \\
\hline Junior middle school (1948) & $0.61(0.32,1.19)$ & Ref. & $1.79(1.41,2.28)$ & $2.89(1.99,4.22)$ & $1.35(0.93,1.96)$ & $1.54(1.04,2.29)$ & Ref. \\
\hline Senior middle school (1428) & $0.32(0.11,0.96)$ & Ref. & $2.00(1.52,2.64)$ & $3.87(2.48,6.04)$ & $1.87(1.21,2.88)$ & $1.41(0.89,2.25)$ & Ref. \\
\hline College degree and above (816) & $0.29(0.06,1.37)$ & Ref. & $1.59(1.10,2.31)$ & $4.46(2.44,8.16)$ & $2.00(1.12,3.57)$ & $1.35(0.73,2.51)$ & Ref. \\
\hline Smoking status & & Ref. & & & & & Ref. \\
\hline no (4294) & $0.48(0.31,0.75)$ & Ref. & $1.75(1.50,2.05)$ & $3.21(2.49,4.15)$ & $1.63(1.27,2.10)$ & $1.46(1.12,1.91)$ & Ref. \\
\hline yes (997) & $0.82(0.39,1.75)$ & Ref. & $1.77(1.25,2.51)$ & $2.97(1.63,5.41)$ & $0.88(0.50,1.56)$ & $1.21(0.66,2.21)$ & Ref. \\
\hline \multicolumn{8}{|l|}{ Drinking status } \\
\hline no (4341) & $0.51(0.34,0.77)$ & Ref. & $1.78(1.52,2.09)$ & $3.54(2.73,4.58)$ & $1.54(1.19,1.99)$ & $1.50(1.14,1.98)$ & Ref. \\
\hline yes (950) & $0.92(0.33,2.56)$ & Ref. & $1.55(1.09,2.20)$ & $1.72(0.95,3.11)$ & $1.28(0.76,2.17)$ & $1.11(0.63,1.94)$ & Ref. \\
\hline \multicolumn{8}{|l|}{ Diabetes mellitus } \\
\hline no (4701) & $0.55(0.36,0.83)$ & Ref. & $1.76(1.51,2.06)$ & $3.29(2.57,4.22)$ & $1.49(1.16,1.91)$ & $1.44(1.10,1.88)$ & Ref. \\
\hline yes (367) & $0.35(0.06,0.17)$ & Ref. & $1.41(0.84,2.37)$ & $2.14(0.95,4.81)$ & $1.46(0.74,2.89)$ & $1.38(0.65,2.92)$ & Ref. \\
\hline unknown (223) & $0.69(0.16,2.98)$ & Ref. & $1.50(0.61,3.66)$ & $2.18(0.41,11.53)$ & $1.51(0.37,6.20)$ & $1.23(0.24,6.12)$ & Ref. \\
\hline
\end{tabular}

Table 2. Adjusted odd ratios $(95 \% \mathrm{CI})$ for hypertension risk according to BMI and physical activity stratified by major characteristics. The multivariate model adjusted for age, sex, BMI $(<18.5,18.5 \sim 23.9,24 \sim 28$,

$\geq 28$ ), physical activity (0 600met-hours/week; 600 1200 met-hours/week; $\geq 1200$ met-hours/week); waist circumference (male, $\leq 90,>90$; female, $\leq 80,>80$ ), marital status, education level, smoking status, drinking status and diabetes mellitus, except for the stratified variable itself. BMI, body mass index.

the odds of hypertension were nearly double (adjusted OR 1.77, 95\% CI 1.53-2.05) in overweight subjects and more than three times higher (adjusted OR 3.23, 95\% CI 2.62-4.13) in obese subjects, however, a protective effect was presented in underweight subjects (adjusted OR 0.47, 95\% CI 0.32-0.69). Multi-adjusted odds for hypertension associated with low, moderate, and high level of physical activity were $1.44(1.17-1.86), 1.40$ (1.09-1.79) and 1.00, respectively. The spline curve in Fig. 1(a) and (b) illustrated that there were nonlinear associations of BMI and physical activity with hypertension risk $(P<0.001)$. Cubic spline regression confirmed the risk of hypertension may be higher with higher BMI and lower level of physical activity.

The joint associations of different levels of BMI and physical activity with the risk of hypertension were showed in Table 4 . The odds of hypertension were $54 \%$ higher in normal weight inactive subjects than in normal weight high active subjects (adjusted OR 1.54, 95\% CI 1.09-2.18). In comparison with normal weight subjects who reported high level of physical activity, subjects who reported both low level of physical activity and had obese weight showed the highest risk of hypertension (adjusted OR 5.89, 95\% CI 3.90-8.88).

\section{Discussion}

In this cross-sectional study, we found that high BMI and low physical activity were independently associated with hypertension in middle-age and older population in China, after adjusting for socioeconomic factors and DM. Moreover, the combined effect of low physical activity and high BMI was associated with the highest risk of hypertension. Third, the study also indicated that high level of physical activity might be a protective factor of hypertension, and it could not offset the risk of obesity, which suggests that preventive interventions including weight control and physical activity are both very important, even among those with normal BMI.

To our knowledge, this study is the first to examine the independent and combined effects of physical activity and BMI on the risk of hypertension simultaneously among Chinese adults. We found that the risk of hypertension accelerated with the increase of BMI, which was similar with other studies ${ }^{7,17-19}$. And it also confirmed that 


\begin{tabular}{|c|c|c|c|}
\hline & OR $(95 \% \mathrm{CI})^{1}$ & Adj-OR $(95 \% \mathrm{CI})^{2}$ & $\operatorname{Adj}-\mathrm{OR}(95 \% \mathrm{CI})^{3}$ \\
\hline \multicolumn{4}{|l|}{ BMI } \\
\hline underweight & $0.62(0.43-0.90)$ & $0.48(0.32-0.71)$ & $0.47(0.32-0.69)$ \\
\hline normal & 1.00 & 1.00 & 1.00 \\
\hline overweight & $1.94(1.71-2.21)$ & $1.77(1.53-2.05)$ & $1.77(1.53-2.05)$ \\
\hline obese & $3.49(2.86-4.26)$ & $3.54(2.65-4.25)$ & $3.23(2.62-4.13)$ \\
\hline \multicolumn{4}{|l|}{ MET } \\
\hline Low & $1.26(1.02-1.57)$ & $1.49(1.18-1.87)$ & $1.44(1.17-1.86)$ \\
\hline Moderate & $1.30(1.03-1.63)$ & $1.40(1.10-1.80)$ & $1.40(1.09-1.79)$ \\
\hline High & 1.00 & 1.00 & 1.00 \\
\hline
\end{tabular}

Table 3. Odds ratios for association between each of BMI and physical activity and risk of hypertension. ${ }^{1}$ Unadjusted. ${ }^{2}$ Adjusted for age, sex, educational level, marital status, smoking status, drinking status, waist and diabetes mellitus. ${ }^{3}$ Adjusted for age, sex, educational level, marital status, smoking status, drinking status, waist, diabetes mellitus and BMI (or physical activity). BMI, body mass index; MET, metabolic equivalent.

(a)

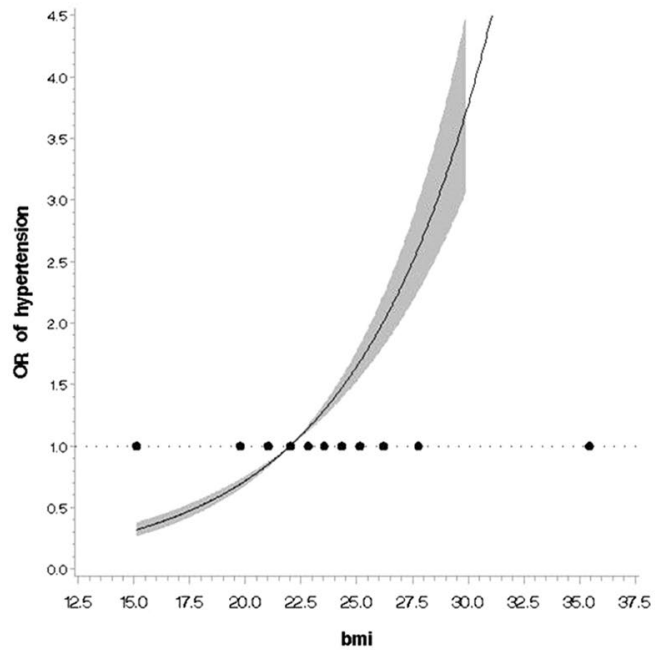

(b)

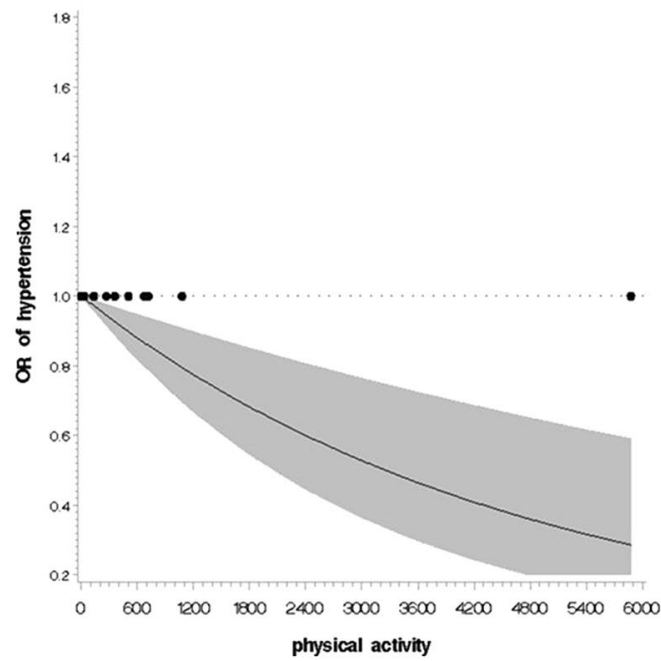

Figure 1. Multivariable adjusted spline curves for relation between BMI, physical activity and risk of hypertension. (a) BMI and risk of hypertension, (b) physical activity and risk of hypertension.

overweight and obesity were risk factors for health, just as we all know. As to the physical activity, our results might be different from some studies in western countries, which reported physical activity was not associated with hypertension. It may be mainly owing to the population with different areas and ethnicity. Besides, metabolic equivalent was calculated using different methods for each activity may also contribute to it.

In addition to indirect effects by reducing body fat, the decrease in risk of hypertension induced by physical activity may be explained through attenuation of adrenergic sympathetic activity ${ }^{20,21}$ accompanied by the decreased systemic vascular resistance ${ }^{22}$, and decreased stroke volume combined with decreased contractility of the heart after exercise ${ }^{23}$. Other possible mechanisms include reduced levels of catecholamines ${ }^{24}$, as well as increased urinary sodium excretion and reduction of total peripheral resistance $\mathrm{e}^{25}$.

As far as we know, only two studies examined the combined effect of BMI and physical activity on hyperten$\operatorname{sion}^{8,9}$, and the results were inconsistent. Gang Hu' study ${ }^{9}$ in Finland showed higher BMI was not associated with hypertension (OR, 1.13, 95\%CI 0.96-1.33 in men; OR, 1.13, 95\%CI 0.96-1.33 in women). In contrast, our study showed a $77 \%$ increase in the risk of hypertension among overweight subjects. The differences between the two studies may be explained in part by the diversity of physical activity measurements and BMI category standard. Besides, BMI was categorized according to the guidelines of Working Group on Obesity in China in our study, however, the previous study according standardized protocol ${ }^{26}$. Similar to Caroline Jackson' study ${ }^{8}$ conducted among Australia women, our findings also found that high levels of physical activity may reduce hypertension risk among overweight and obese population, but could not completely negate the increased risk of hypertension associated with overweight and obesity, which could provide new perspectives for hypertensive population.

There are some limitations in our study. First, the assessment of physical activity is self-reported and thus is imprecise. Misclassification is inevitable and may result in an under/over-estimation of the association of physical activity with the risk of hypertension. Second, the results of the present study are limited to middle-aged and older people and thus the findings cannot necessarily be extrapolated to younger people or other ethnicities. Further 


\begin{tabular}{|l|l|l|l|}
\hline \multirow{4}{*}{ BMI } & \multicolumn{3}{l}{ physical activity } \\
\cline { 2 - 4 } & low & moderate & high \\
\hline Unadjusted odds ratios (95\% CI) \\
\hline underweight & $0.68(0.40-1.15)$ & $1.31(0.60-2.85)$ & $0.38(0.05-3.03)$ \\
\hline normal & $1.18(0.84-1.63)$ & $1.47(1.04-2.09)$ & 1.00 \\
\hline overweight & $2.58(1.86-5.38)$ & $2.18(1.53-3.10)$ & $2.01(1.30-3.1)$ \\
\hline obese & $4.87(3.35-7.08)$ & $3.51(2.15-5.73)$ & $2.58(1.25-5.33)$ \\
\hline Adjusted odds ratios $(\mathbf{9 5 \%} \mathbf{C I})^{\mathrm{a}}$ & \multicolumn{3}{l}{} \\
\hline underweight & $0.65(0.37-1.13)$ & $1.25(0.54-2.89)$ & $0.33(0.04-2.83)$ \\
\hline normal & $1.54(1.09-2.18)$ & $1.70(1.17-2.45)$ & 1.00 \\
\hline overweight & $2.91(2.04-4.14)$ & $2.45(1.68-3.57)$ & $2.22(1.40-3.53)$ \\
\hline obese & $5.89(3.90-8.88)$ & $3.91(2.30-6.64)$ & $3.00(1.39-6.50)$ \\
\hline
\end{tabular}

Table 4. Odds ratios for the joint effect of BMI and physical activity on risk of hypertension. a Adjusted for age, sex, educational level, marital status, smoking status, drinking status, waist and diabetes mellitus. BMI, body mass index.

study is therefore warranted in more diverse populations. Third, although a number of confounders were adjusted in our study, there were still some other factors which were not included such as consumption of diet the family history of hypertension, which was also reported to be associated with hypertension risk in other studies ${ }^{27,28}$. Finally, this is cross-sectional study and thus the causal association of BMI and physical activity and risk of hypertension should be further examined in large cohort studies.

\section{Conclusion}

In summary, both elevated BMI and reduced physical activity appear to play an important role in the risk of hypertension. The highest risk of hypertension was in obese subjects, who reported low level of physical activity, and the risk of hypertension associated with overweight and obesity may be reduced considerably by increased physical activity levels. Besides, there is a higher risk of hypertension among low physical activity subjects with normal weight population.

\section{Methods}

Ethical Approval. Our study was approved by the Ethics Committee of Tongji Medical College Institutional review Board, Tongji Medical College, Huazhong University of Science and Technology (Wuhan, Hubei, China) and was carried out in accordance with the principles of the Declaration of Helsinki. All the participants were provided with the informed consent before participation in the study, and all questionnaires were filled in by participants anonymously.

Study design and population. The survey was conducted in Zhuhai and Shenzhen city, two cities in Southeast China from October 2013 to December 2015. It was aimed to provide information for community diagnosis for local health sectors. Respondents were selected using multi-stage sampling method, and face-to-face interviews were conducted by trained local interviewers using a questionnaire to subjects with informed consent. The information of socio-economic characteristics, health status and health risk factors were collected and physical examination was also conducted among participants in community health service centers for blood pressure, height, weight and waist circumference. Eligible participants for the study were people over 40 years old in the survey.

Ascertainment of hypertension. Blood pressure was measured via mercury sphygmomanometer and the participants were in sitting position. Each participant was examined three times of resting blood pressure in this study. All measurements and medical examinations were performed by trained nurses or physicians. Individuals were defined as hypertensive if they met one of the following standards: (1) self-reported physician diagnosis of hypertension; (2) self-reported current use of an antihypertensive medication; (3) mean value of systolic blood pressure (SBP) above $140 \mathrm{mmHg}$ or/and diastolic blood pressure (DBP) above $90 \mathrm{mmHg}$ measured in the medical examination.

Assessment of BMI, Physical Activity and Covariates. BMI was computed as weight in kilograms divided by height in meters squared. During the analysis, the BMI category was categorized as underweight $\left(<18.5 \mathrm{~kg} \mathrm{~m}^{-2}\right)$, normal weight $\left(18.5-23.9 \mathrm{~kg} \mathrm{~m}^{-2}\right)$, overweight $\left(24-27.9 \mathrm{~kg} \mathrm{~m}^{-2}\right)$ and obesity $\left(\geq 28 \mathrm{~kg} \mathrm{~m}^{-2}\right)$ based on the guidelines of Working Group on Obesity in China ${ }^{29}$.

Frequency and average duration of each type of physical activity were obtained via the questionnaires: walking, biking, tai chi, qi gong, jogging, swimming, dancing, and playing basketball, badminton, or soccer. To estimate total energy expenditure (TEE) from physical activity, separate metabolic equivalent (MET) minutes per week were calculated for each activity according to the following formulas: MET coefficient of activity*duration (minutes per time)* frequency (times per week). Using the compendium of physical activities, METs per hour used for leisure activities were: 3 for walking, 4 for biking, 4.5 for tai chi and qi gong, 5.0 for dancing, 6.0 for doing exercise in gym, 7.0 for jogging, swimming and playing ball games ${ }^{30}$. The physical activity was divided into three groups according to the TEE: $<600 \mathrm{MET}$ - min/week, 600-1200 MET- min/week, and $\geq 1200 \mathrm{MET}$ - min/week. 
Waist circumference was recorded in centimeters and measured with the subject standing and wearing only underwear, using a nonstretching measuring tape positioned at the level midway between the lower edge of the last $\mathrm{rib}$ and the upper portion of the iliac crest. Waist circumference values of up to $90 \mathrm{~cm}$ in males and $80 \mathrm{~cm}$ in females were considered normal ${ }^{31}$. Other variables that may be associated with hypertension were obtained from the survey. The following were used as adjustment variables: age, gender, educational level, marital status, current smoking status, current drinking status, diabetes mellitus (DM) diagnosed by a physician were reported by the participants.

Statistical Analysis. Sociodemographic characteristics of the participants were reported as mean (standard deviation, SD) for continuous variables and as number (percentages) for categorical variables. Logistic regressions were performed to evaluate the independent and combined associations of BMI and physical activity with hypertension. Covariates included age, gender, marital status, educational level, DM, smoking status, drinking status, physical activity, waist circumference, and BMI category. The results were presented as odd ratios (ORs) with $95 \%$ confidence intervals (CIs), with BMI of 18.5-23.9 and physical activity of $\geq 1200$ MET-min/week as the reference groups. Nonlinear trends of hypertension risk were tested by restricted cubic spline logistic regression using 3 knots placed at the 10th, 50th, and 90th percentiles of BMI and physical activity, respectively, with 22 for BMI and $0 \mathrm{MET}-\mathrm{min} /$ weeks for physical activity as the reference groups. Stratified analyses were performed by baseline characteristics (including age $(<60, \geq 60$ years), sex, waist circumference (normal, abnormal), marital status (single, married, divorce, widowed, other), educational level (primary school and below, junior middle school, senior middle school, college degree and above), current smoking (yes, no), current drinking (yes, no), DM (yes, no). Additionally, we tested the potential interaction by adding interaction terms of these covariates with BMI or physical activity, respectively. Moreover, we also estimated the combined effects of BMI and physical activity on the risk of hypertension, taking BMI 18.5-23.9 and physical activity 600-1200 MET-min/week as the reference category. All statistical analyses were performed using SAS version 9.3 software (SAS institute Inc., Cary, NC). A two-tailed $P$-value $<0.05$ was considered statistically significant.

Data Availability. The datasets generated during and/or analyzed during the current study are available from the corresponding author on reasonable request.

\section{References}

1. Staessen, J. A., Wang, J., Bianchi, G. \& Birkenhager, W. H. Essential hypertension. Lancet (London, England) 361, 1629-1641, doi:10.1016/s0140-6736(03)13302-8 (2003).

2. Fields, L. E. et al. The burden of adult hypertension in the United States 1999 to 2000: a rising tide. Hypertension (Dallas, Tex.: 1979) 44, 398-404, doi:10.1161/01.hyp.0000142248.54761.56 (2004).

3. Kearney, P. M. et al. Global burden of hypertension: analysis of worldwide data. Lancet (London, England) 365, 217-223, doi:10.1016/ s0140-6736(05)17741-1 (2005).

4. Wu, X. et al. Prevalence of hypertension and its trends in Chinese populations. International journal of cardiology 52, 39-44 (1995).

5. Wang, J. G. \& Li, Y. Characteristics of hypertension in the Chinese population. Current hypertension reports 14, 410-415, doi:10.1007/s11906-012-0288-1 (2012).

6. Hajjar, I. \& Kotchen, T. A. Trends in prevalence, awareness, treatment, and control of hypertension in the United States, 1988-2000. Jama 290, 199-206, doi:10.1001/jama.290.2.199 (2003).

7. Shihab, H. M. et al. Body mass index and risk of incident hypertension over the life course: the Johns Hopkins Precursors Study. Circulation 126, 2983-2989, doi:10.1161/circulationaha.112.117333 (2012).

8. Jackson, C., Herber-Gast, G. C. \& Brown, W. Joint effects of physical activity and BMI on risk of hypertension in women: a longitudinal study. Journal of obesity 2014, 271532, doi:10.1155/2014/271532 (2014)

9. Hu, G. et al. Relationship of physical activity and body mass index to the risk of hypertension: a prospective study in Finland. Hypertension (Dallas, Tex.: 1979) 43, 25-30, doi:10.1161/01.hyp.0000107400.72456.19 (2004).

10. Carnethon, M. R. et al. Joint associations of physical activity and aerobic fitness on the development of incident hypertension: coronary artery risk development in young adults. Hypertension (Dallas, Tex.: 1979) 56, 49-55, doi:10.1161/ hypertensionaha.109.147603 (2010).

11. Huai, P. et al. Physical activity and risk of hypertension: a meta-analysis of prospective cohort studies. Hypertension (Dallas, Tex.: 1979) 62, 1021-1026, doi:10.1161/hypertensionaha.113.01965 (2013).

12. Semlitsch, T. et al. Increasing physical activity for the treatment of hypertension: a systematic review and meta-analysis. Sports medicine (Auckland, N.Z.) 43, 1009-1023, doi:10.1007/s40279-013-0065-6 (2013).

13. Paffenbarger, R. S. Jr., Wing, A. L., Hyde, R. T. \& Jung, D. L. Physical activity and incidence of hypertension in college alumni. American journal of epidemiology 117, 245-257 (1983)

14. Haapanen, N., Miilunpalo, S., Vuori, I., Oja, P. \& Pasanen, M. Association of leisure time physical activity with the risk of coronary heart disease, hypertension and diabetes in middle-aged men and women. International journal of epidemiology 26, $739-747$ (1997).

15. Pereira, M. A. et al. Physical activity and incident hypertension in black and white adults: the Atherosclerosis Risk in Communities Study. Preventive medicine 28, 304-312 (1999).

16. Hayashi, T. et al. Walking to work and the risk for hypertension in men: the Osaka Health Survey. Annals of internal medicine 131, 21-26 (1999)

17. Gelber, R. P., Gaziano, J. M., Manson, J. E., Buring, J. E. \& Sesso, H. D. A prospective study of body mass index and the risk of developing hypertension in men. American journal of hypertension 20, 370-377, doi:10.1016/j.amjhyper.2006.10.011 (2007).

18. Rankinen, T., Church, T. S., Rice, T., Bouchard, C. \& Blair, S. N. Cardiorespiratory fitness, BMI, and risk of hypertension: the HYPGENE study. Medicine and science in sports and exercise 39, 1687-1692, doi:10.1249/mss.0b013e31812e527f (2007).

19. Wang, M., Chu, C. \& Mu, J. Relationship between body mass index changes and blood pressure changes from childhood to adulthood in a general Chinese population: a 26 year cohort follow-up study. Blood pressure 25, 319-326, doi:10.3109/08037051.20 16.1168969 (2016).

20. Chia, K. S., Wong, P. K., Faux, S., McLachlan, C. S. \& Kotlyar, E. The Benefit of Exercise Training in Pulmonary Hypertension: a Clinical Review. Internal medicine journal. doi:10.1111/imj.13159 (2016).

21. Reid, C. M., Dart, A. M., Dewar, E. M. \& Jennings, G. L. Interactions between the effects of exercise and weight loss on risk factors, cardiovascular haemodynamics and left ventricular structure in overweight subjects. Journal of hypertension 12, 291-301 (1994).

22. Bond, V. Jr. et al. Exercise blood pressure response and skeletal muscle vasodilator capacity in normotensives with positive and negative family history of hypertension. Journal of hypertension 12, 285-290 (1994).

23. Ketelhut, R., Losem, C. J. \& Messerli, F. H. Is a decrease in arterial pressure during long-term aerobic exercise caused by a fall in cardiac pump function? American heart journal 127, 567-571 (1994). 
24. Dubbert, P. M., Martin, J. E., Cushman, W. C., Meydrech, E. F. \& Carroll, R. G. Endurance exercise in mild hypertension: effects on blood pressure and associated metabolic and quality of life variables. Journal of human hypertension 8, 265-272 (1994).

25. Arakawa, K. Hypertension and exercise. Clinical and experimental hypertension (New York, N. Y.: 1993) 15, 1171-1179 (1993).

26. The World Health Organization MONICA Project (monitoring trends and determinants in cardiovascular disease): a major international collaboration. WHO MONICA Project Principal Investigators. Journal of clinical epidemiology 41, 105-114 (1988).

27. Appel, L. J. et al. A clinical trial of the effects of dietary patterns on blood pressure. DASH Collaborative Research Group. The New England journal of medicine 336, 1117-1124, doi:10.1056/nejm199704173361601 (1997).

28. Williams, R. R. et al. Are there interactions and relations between genetic and environmental factors predisposing to high blood pressure? Hypertension (Dallas, Tex.: 1979) 18, I29-37 (1991).

29. Zhou, B. F. Predictive values of body mass index and waist circumference for risk factors of certain related diseases in Chinese adults-study on optimal cut-off points of body mass index and waist circumference in Chinese adults. Biomedical and environmental sciences: BES 15, 83-96 (2002).

30. Ainsworth, B. E. et al. 2011 Compendium of Physical Activities: a second update of codes and MET values. Medicine and science in sports and exercise 43, 1575-1581, doi:10.1249/MSS.0b013e31821ece12 (2011).

31. Alberti, K. G., Zimmet, P. \& Shaw, J. Metabolic syndrome-a new world-wide definition. A Consensus Statement from the International Diabetes Federation. Diabetic medicine: a journal of the British Diabetic Association 23, 469-480, doi:10.1111/j.1464-5491.2006.01858.x (2006).

\section{Acknowledgements}

We thank all staff members involved in this study for their painstaking efforts in conducting the data collection. Fundamental Research Funds for the Central Universities, Huazhong University of Science and Technology (2016YXMS215), Wuhan, China.

\section{Author Contributions}

W.Z.L. and Z.X.L. conceived and designed the study. C.M.W. and W.Z.L. participated in the acquisition of data. W.Z.L. and D.M.W. analyzed the data. W.Z.L. drafted the manuscript. D.M.W., O.M.S. and Y.F.Z. helped to revise the paper. All authors read and approved the final manuscript. Z.X.L. is the guarantor of this work and had full access to all the data in the study.

\section{Additional Information}

Competing Interests: The authors declare that they have no competing interests.

Publisher's note: Springer Nature remains neutral with regard to jurisdictional claims in published maps and institutional affiliations.

Open Access This article is licensed under a Creative Commons Attribution 4.0 International License, which permits use, sharing, adaptation, distribution and reproduction in any medium or format, as long as you give appropriate credit to the original author(s) and the source, provide a link to the Creative Commons license, and indicate if changes were made. The images or other third party material in this article are included in the article's Creative Commons license, unless indicated otherwise in a credit line to the material. If material is not included in the article's Creative Commons license and your intended use is not permitted by statutory regulation or exceeds the permitted use, you will need to obtain permission directly from the copyright holder. To view a copy of this license, visit http://creativecommons.org/licenses/by/4.0/.

(c) The Author(s) 2017 